\title{
Non-Destructive Investigation of Composition, Chemical Properties and Structure of Materials by Synchrotron Radiation
}

\author{
Wolf GÖRNER, Ralf MATSCHAT, Martin RADTKE, Uwe REINHOLZ, Heinrich \\ RIESEMEIER, Federal Institute of Materials Research and Testing, Berlin, Germany \\ Maik EICHELBAUM, Klaus RADEMANN, Humboldt University, Institute of Chemistry, \\ Berlin, Germany
}

\section{Introduction}

Synchrotron radiation has (partly unique) properties promoting the investigation of solids and interfaces on a broad scale. This can support the development of new materials among them certified reference materials (CRMs). Due to the high intensity and the minute size of the light source the radiation can be filtered (monochromatized) and/or focussed onto the sample. Samples can be scanned at high resolution $(\approx 2 \mu \mathrm{m})$ with optimum X-ray energy. Moreover, the high degree of polarization (linear, circular, elliptic) allows to study magnetic properties e.g. of layered structures[1].

Computer assisted tomography (CT) based on X-ray absorption avoids artefacts caused by beam hardening using monochromatic radiation [2].

Refraction of X-rays tells us a lot about interior interfaces, their flaws, their behaviour under load or about the high cycle fatigue of compound materials like carbon fibre reinforced plastics. Refraction or small angle X-ray scattering (SAXS) make use of the high parallelity of the synchrotron light and can be combined with a scanning regime resulting in topographic images of down to submicron resolution [3]. One can learn a lot about surface near regions from electron spectroscopy after excitation by synchrotron radiation [4]. X-ray microscopy within the so called "water window" (between the K-edges of carbon and oxygen) makes tiny biostructures visible [5].

The mentioned group of examples is by far not complete. From the numerous interactions of synchrotron radiation with matter only absorption, reflection and fluorescence will be dealt with in this contribution.

\section{The BAMline at BESSY}

The heart of the beamline configuration of the BAM at BESSY, called BAMline, is the 7 Tesla-wavelength shifter (WLS) located in the 1.7 (1.9) GeV - electron storage ring. Due to its high magnetic field strength the WLS acts as a photon source with a much harder X-ray spectrum than the bending magnets (BM) of the storage ring (see Fig. 1a, note log scale).

So the spectral range up to $80 \mathrm{keV}$ is made accessible even at a "soft" synchrotron. The energy spectrum and the shape of the photon beam at the exit of the BAMline is controlled by optical elements having a filter function and/or ruling the optical conditioning such as 
focusing or collimation. A stack of absorbers realize various low energy cutoffs (pink beam) and take off part of the heat burden. The double multilayer monochromator (DMM), offering a bandwidth of $1.5 \%$ (rel.), is very suitable for high flux applications and operates as an effective prefilter for the double crystal monochromator. The latter may be equipped with various crystal pairs showing bandwidths between $0.02 \%$ and $0.005 \%$ (rel.), which are prerequisites for X-ray diffraction (XRD) and X-ray absorption spectrometry (XAS).

a)
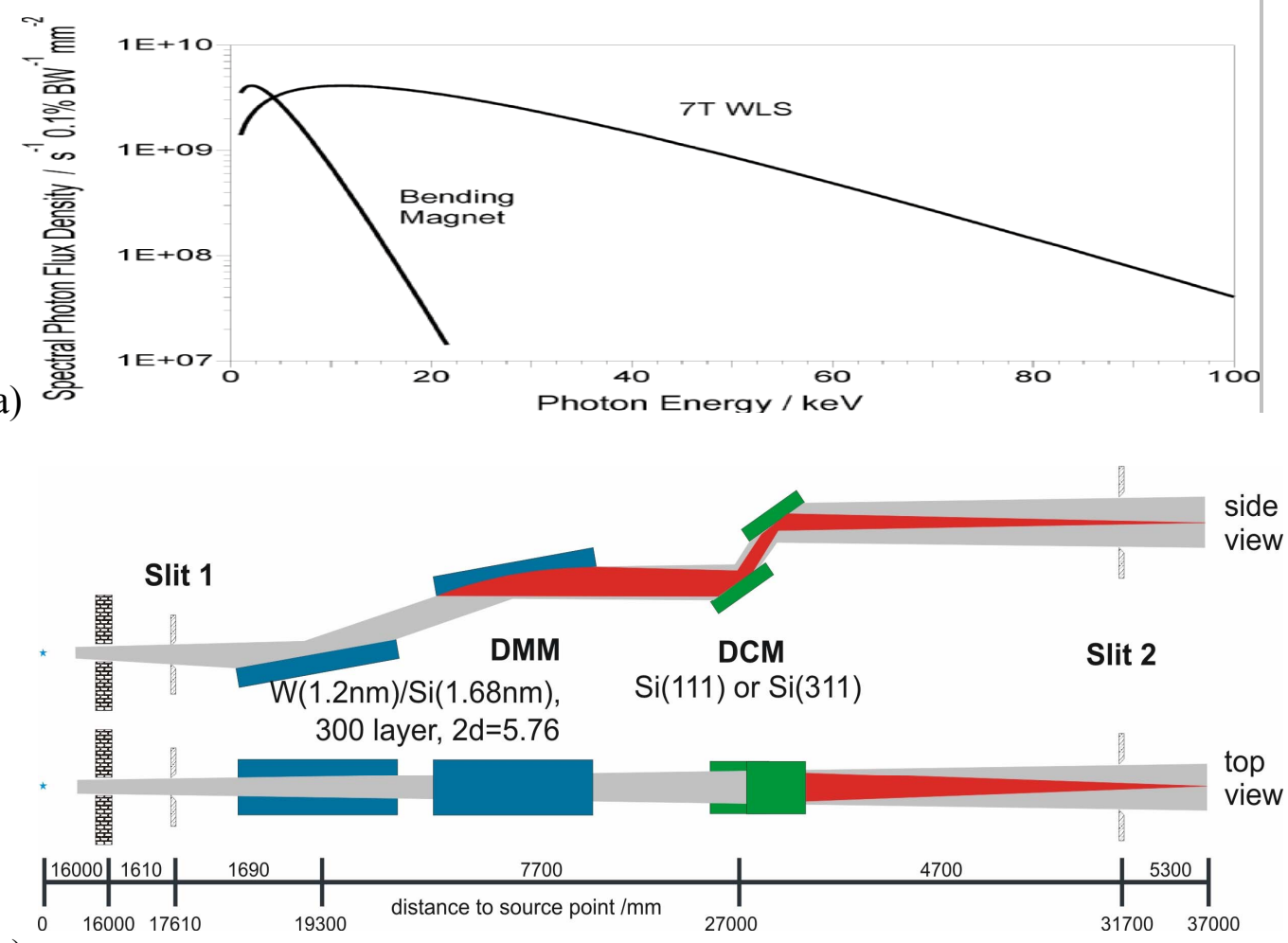

b)

Fig. 1 a) The spectral photon flux density of the WLS in comparison with a bending magnet source. b) The principle set up and dimensions of the BAMline.

Finally, crossed slits cut a window out of the beam. The window size may vary from $10 \mu \mathrm{m}$ x $10 \mu \mathrm{m}$ up to the $1 \mathrm{~mm} \times 1 \mathrm{~mm}$ range. The principal set up can be seen in Fig. 1b [6].

At the WLS a microfocus beamline will start operating in the near future. Its advantage over the BAMline is focusing $(10-20 \mu \mathrm{m})$ at high bandwidth, respectively high photon flux. The microfocus is especially suited for speedy scanning in order to perform laterally resolved SAXS or XRS. Using its narrow band mode it allows highly resolved X-ray absorption spectrometry (XAS) [7].

Tab. 1 : Parameters of the BAMline

\begin{tabular}{|c|c|c|c|c|}
\hline & $\begin{array}{c}\text { Energy range } \\
\mathrm{keV}\end{array}$ & $\begin{array}{c}\text { Spot size } \\
\mu \mathrm{m}\end{array}$ & $\begin{array}{c}\text { Photon Flux Density } \\
\mathrm{s}^{-1} \mathrm{~mm}^{-2}\end{array}$ \\
\hline & & & $10 \mathrm{keV}$ & $20 \mathrm{keV}$ \\
\hline DMM & $4-80$ & 100 (vertical) & $2 \times 10^{12}$ & $1 \times 10^{12}$ \\
\hline DCM Si111 & $4-60$ & & $4.5 \times 10^{8}$ & $4 \times 10^{8}$ \\
\hline bent & $4-22$ & 250 (horiz.) & $5 \times 10^{11}$ & $1 \times 10^{11}$ \\
\hline DCM Si311 & $4-60$ & & $1 \times 10^{8}$ & $1 \times 10^{8}$ \\
\hline bent & $8-50$ & 250 (horiz.) & $8 \times 10^{10}$ & $4 \times 10^{10}$ \\
\hline
\end{tabular}




\section{Reflectometry}

In modern technology nanometer layers play a role of growing importance. It is obvious that it is worthwhile to know their properties like mean thickness or their composition very well.

Due to its omnipresence hydrogen will be found in those layers independently from the production technology such as electrochemical or vapour deposition. Hydrogen is very mobile and can act as an atomic marker. For this purpose the nuclear reaction

${ }^{1} \mathrm{H}\left({ }^{15} \mathrm{~N}, \alpha \gamma\right){ }^{12} \mathrm{C}$

is made use of, bombarding the sample with accelerated ${ }^{15} \mathrm{~N}$-ions. As the differential cross section $\mathrm{d} \sigma(\mathrm{E}) / \mathrm{dE}$ of the above reaction has the shape of a narrow spike at the resonance energy $\mathrm{E}_{\text {res }}=6,385 \mathrm{MeV}$ hydrogen depth profiling becomes possible due to the continuous energy loss of the ${ }^{15} \mathrm{~N}$ ions in matter, when tuning their primary energy.

A diamond-like carbon (DLC) layer on silicon was investigated. The measured intensity of the $\gamma$-quanta $\mathrm{N}_{\gamma} / \mathrm{N}_{\text {ion }}\left(\mathrm{N}_{\gamma} / \mathrm{N}_{\text {ion }}: \gamma\right.$-yield per incident ions) in dependence on the energy of the ${ }^{15} \mathrm{~N}$ ions delivered a rectangular profile over the energy range $\Delta \mathrm{E}$, which amounted to $(323 \pm 3) \mathrm{keV}$ in that case (see Fig. 2a).

The absolute hydrogen content $\mathrm{c}_{\mathrm{H}} \sim \mathrm{S} \cdot \mathrm{N}_{\gamma} / \mathrm{N}_{\text {ion }}$ can only be determined, if $\mathrm{S}$, the stopping power, is known. $S$ describes the energy loss of the ions with path length: $S=\mathrm{dE}_{\text {ion }} / \mathrm{dx}$. The transition to finite path lengths delivers $\mathrm{S}=\Delta \mathrm{E} / \mathrm{d}$. As $\Delta \mathrm{E}$ is known from the profile, the layer thickness $\mathrm{d}$ has to be still determined.

Therefore, synchrotron radiation based X-ray reflectometry was performed. Depending on the constructive / destructive superposition of coherent waves, reflected at the surface and at the interface, respectively, a sinusoidal variation of the reflectivity in dependence on the reflection angle is observed, showing a large number of maxima/minima (see Fig. 2b). d may easily be determined from the angular distance between neighbouring extrema. With $\mathrm{d}$ $=(219 \pm 7) \mathrm{nm}$ (Fig. $2 \mathrm{c}$ ) the stopping power can directly be quantified: $\mathrm{S}=1,475 \mathrm{keV} / \mathrm{nm}$. Now the yield of $\gamma$-quanta per incident ion can be converted into the absolute hydrogen content using the equation mentioned above.

On this basis certified reference materials (CRMs) for hydrogen are under preparation at BAM [8].

\section{Energy Dispersive X-Ray Fluorescence}

The certification of reference materials is one of the main tasks of BAM. Among them CRMs of chemical composition play the dominant role. In a first step a CRM candidate is subjected to a homogeneity test. If the result fulfils the preset conditions the real certification scheme is carried through, drawing benefit from the experience of several laboratories and the capability and independence of various chemical analytical methods. Although non-destructive procedures are very welcome as their "chemical yield" equals unity, energy dispersive X-ray spectrometry EDXRS has been excluded traditionally from the certification process. This is caused by the risk of spectral superposition or incorrect background subtraction. Moreover, new CRMs must not be traced back to existing ones, but to the Système International (SI) d'unités . 


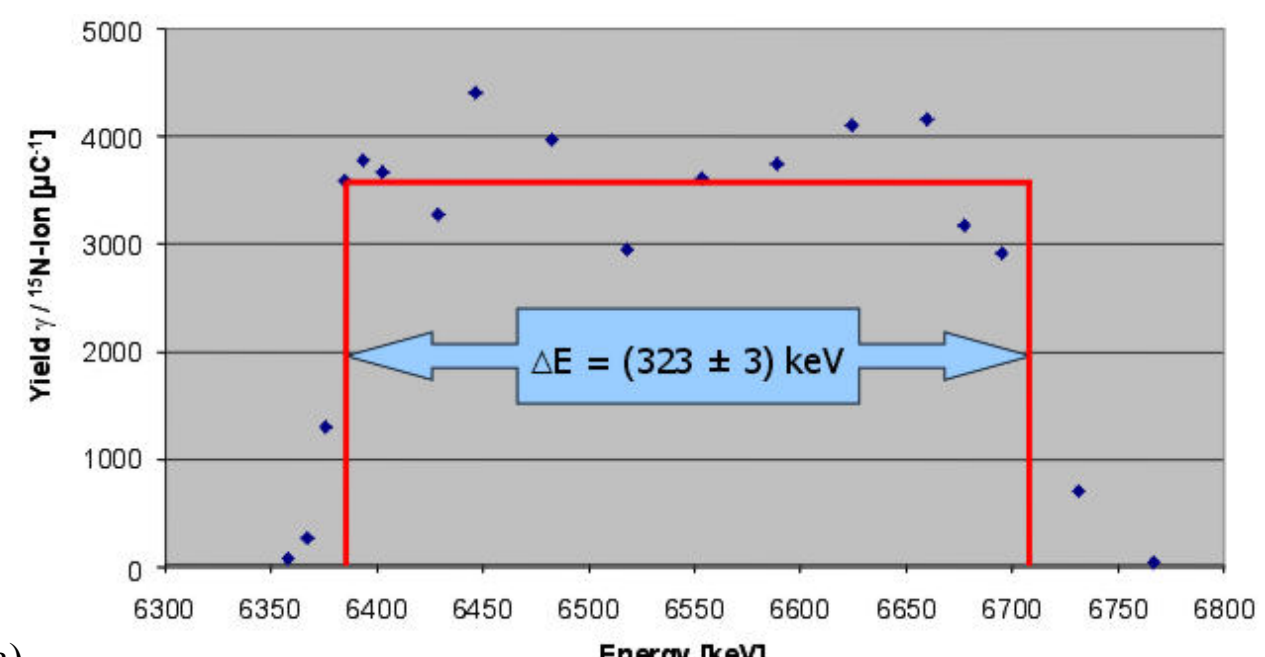

a)

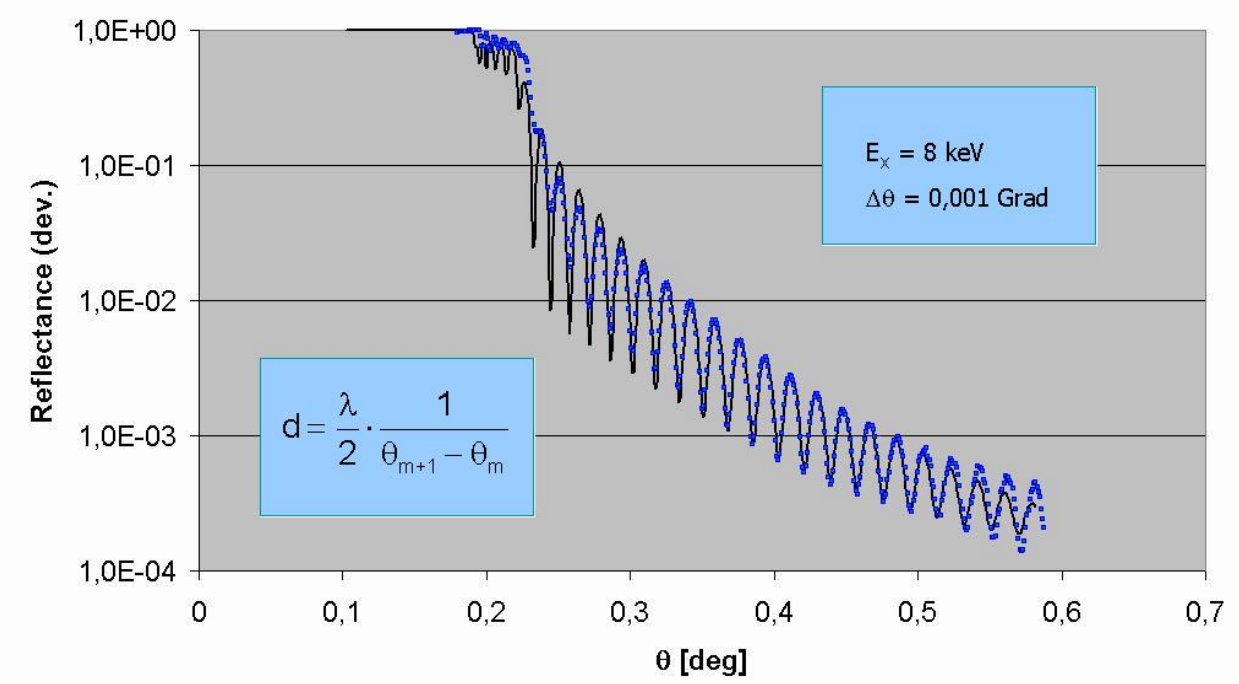

b)

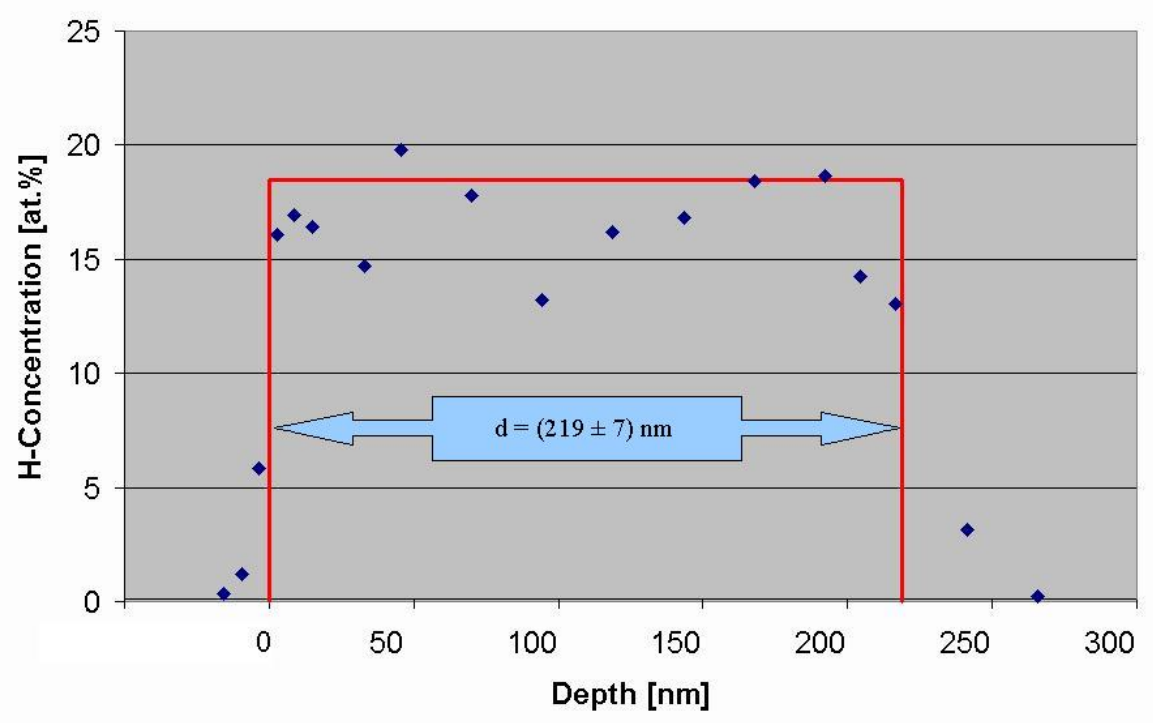

Fig. 2 a) Hydrogen concentration vs. energy of a DLC-layer b) Reflectogram c) Hydrogen depth profile 
The objective is now to qualify synchrotron radiation based EDXRS to become a certifying method. Hereby monochromaticity of radiation and selection of appropriate radiation energy are indispensable tools.

The use of SyXRF for certification has been successfully demonstrated for trace element contents in pure copper and in an Al-alloy. Based on measurements of pure and thick samples of the main constituents a calibration curve can be constructed for every trace element to be analysed, called analyte.

For the first time analyses delivered by SyXRF were included into a certification report of a national metrological institute (NMI) worldwide (see Fig. 3a and $3 \mathrm{~b}$ ) and contributed to certified values $[9,10]$.

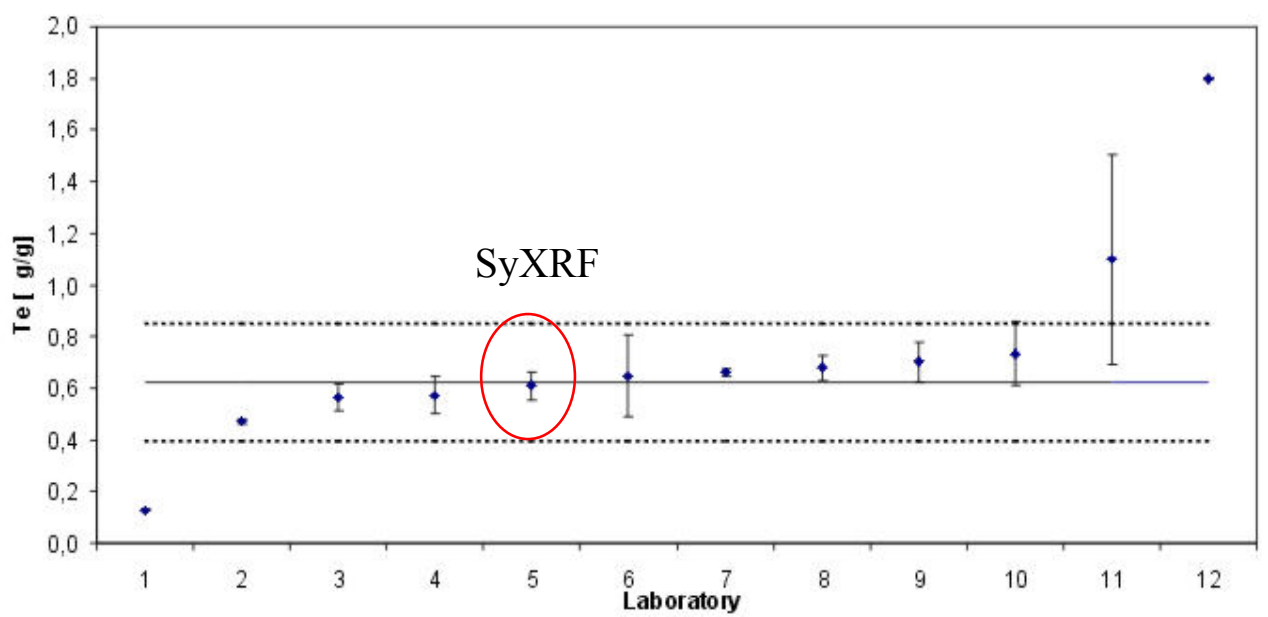

a)

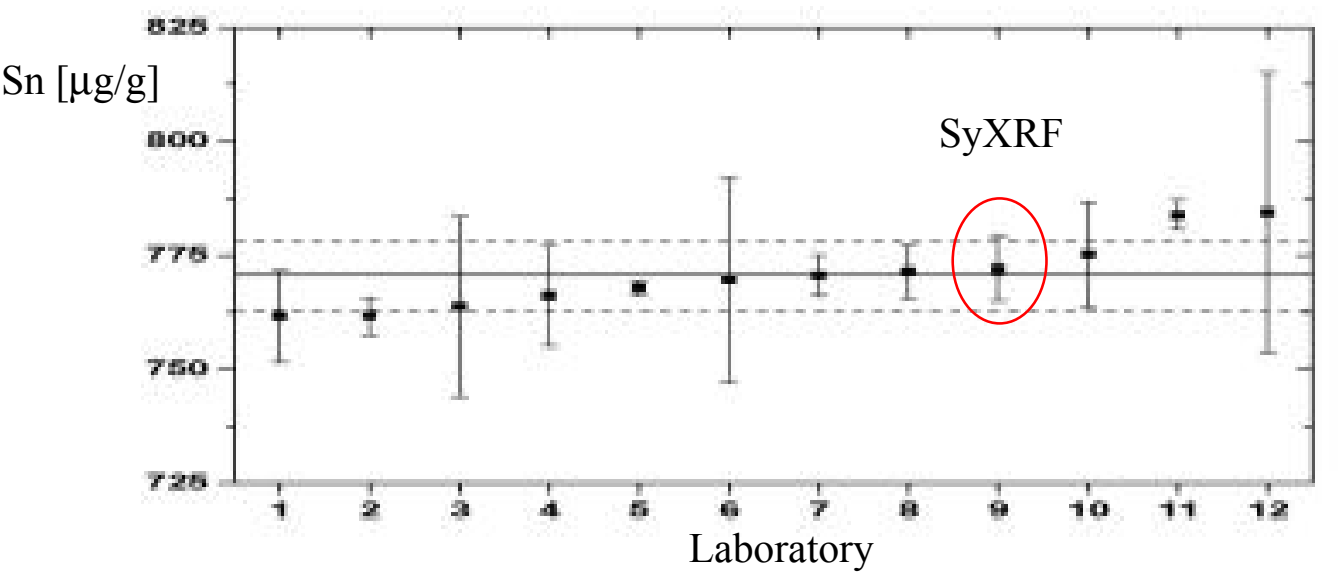

b)

Fig. 3 Graphs of the results of the certification of Te in pure $\mathrm{Cu}$ (Reference material BAM-M382 and $\mathrm{Sn}$ in AlSi9Cu3 (Reference Material BAM-M315). The SyXRF results are in excellent agreement with the result of the certification process.

\section{X-Ray Absorption Near Edge Spectroscopy of Chromium}

As already mentioned, a legal task of BAM is the certification of CRMs. There is a growing demand to "species" CRMs, in which not only the concentration of an element but also the fractions of its different chemical bonding forms are certified. The reason is, that properties like toxicity or receptivity at food intake may tremendously depend on the chemical 
bonding of the element. Popularly speaking, John can not improve his body iron status by sucking a rusty nail. Consequently, ruling boards have fixed thresholds for element species in packing materials such as glass for bottles. In order to guarantee the fulfilling of these legal demands, adequate species CRMs and on-site methods of analytical chemistry will have to be developed more and more in the future.

A given example is the determination of $\mathrm{Cr}(\mathrm{III})$ - and $\mathrm{Cr}(\mathrm{VI})$ - contents in glass produced for containers. Chromium is regarded as carcinogenic and causing allergies. $\mathrm{Cr}(\mathrm{VI})$ is considered 100 times more toxic than $\mathrm{Cr}$ (III) Thus, it is necessary to differentiate between $\mathrm{Cr}(\mathrm{III})$ - and $\mathrm{Cr}(\mathrm{VI})$ - contents. For this purpose a CRM was developed in a collaborative work of BAM and International Commission on Glass (ICG) [11]. In this CRM the mass fractions of total chromium and of hexavalent chromium are certified, the latter based on a wet chemical method developed by ICG [12]. As the availability of an independent and even non-destructive analytical method is always worthwhile in analytical chemistry, Xray absorption near edge spectroscopy (XANES) was applied to the CRM and to three other glass samples. XANES is performed by fine tuning of the energy of incoming photons in steps of $1 \mathrm{eV}$ over the range around the $\mathrm{Cr} \mathrm{K}$-edge using a highly resolving double crystal monochromator (DCM) and measuring the fluorescence radiation by a $\mathrm{Si}(\mathrm{Li})$-detector. The resulting curve shape differs in detail from those presented in most textbooks for the Kedge absorption behaviour. The slight deviations, peaks and wiggles apart from the "rectangular" K-edge are the consequence of multiple scattering of the low kinetic energy photoelectrons by neighbouring atoms. The following information can be drawn from the data in general:

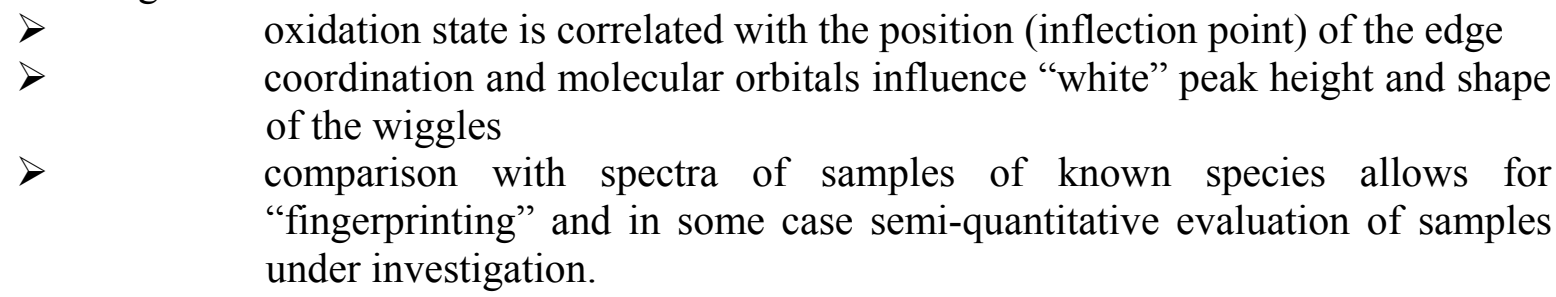

The XANES spectra are displayed in Fig 4. Fortunately, Cr(VI) exposes a pre-edge peak, which is minute and shifted to a somewhat lower energy in the $\mathrm{Cr}(\mathrm{III})$ - spectrum.

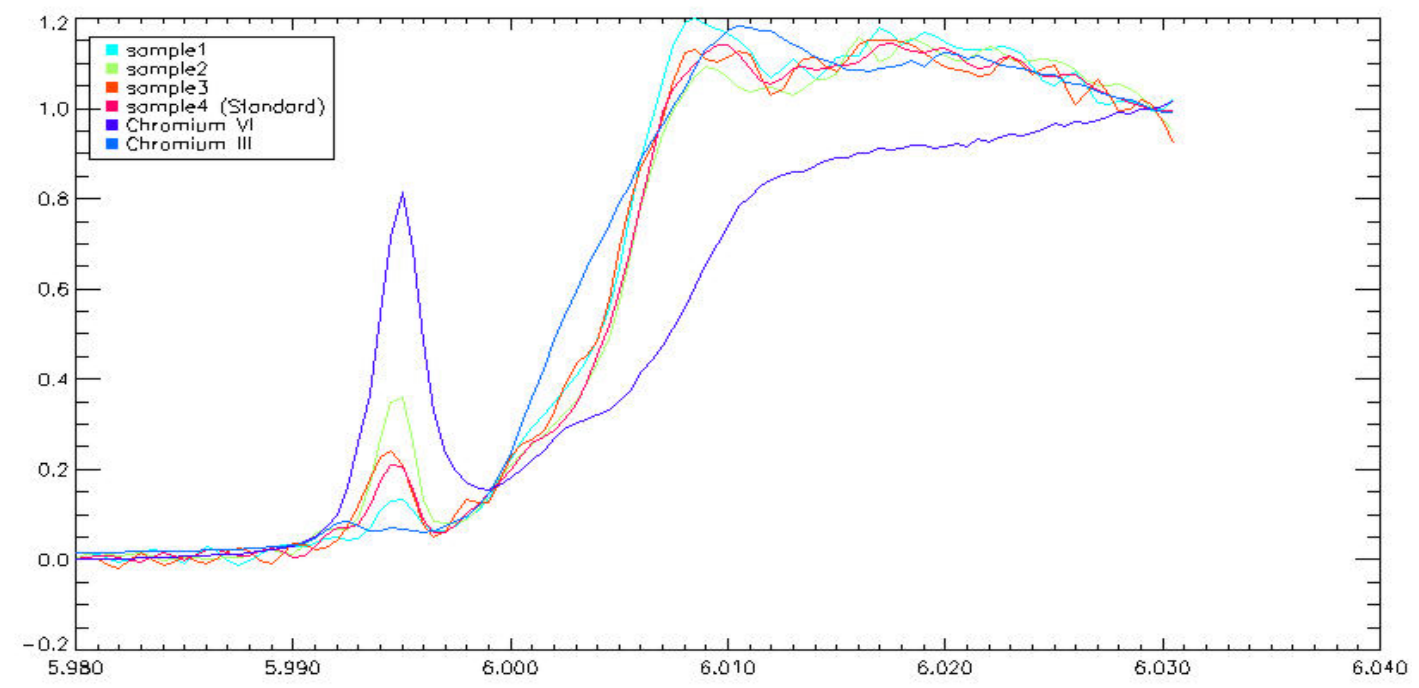

Fig. 4 Comparison of the XANES spectra of $\mathrm{Cr}(\mathrm{III}), \mathrm{Cr}(\mathrm{VI})$ and the examined glass samples. Note the shift of the pre-peak for sample 3.

This feature allows even the quantitation of the $\mathrm{Cr}(\mathrm{VI})$ - fraction as the height of the edge is proportional to the total Cr-content. Table 2 confronts the XANES results with those of the chemical separation method. The $\mathrm{Cr}(\mathrm{VI}) / \mathrm{Cr}$ - value of the CRM BAM-S004 is confirmed 
by XANES. Moreover, the values of samples 1 and 2 coincide well. But for sample 3 a sharp discrepancy was observed, which can not be explained by statistical scattering (XANES: $3 \sigma=4 \%$ rel.). As the chemical method delivered likewise reproducible results, there must be a systematic reason. It may be assumed, that there might exist a Cr valence fraction other than $\mathrm{Cr}(\mathrm{III})$ or $\mathrm{Cr}(\mathrm{VI})$. According to LAY et al. [13] the relative intensity of the prepeak (compared to the edge height) is 0.085 for $\mathrm{Cr}(\mathrm{IV})$ and $0.46 \mathrm{for} \mathrm{Cr}(\mathrm{V})$, whereas own measurements gave 0.83 for $\mathrm{Cr}(\mathrm{VI})$. If $\mathrm{Cr}(\mathrm{IV})$ and/or $\mathrm{Cr}(\mathrm{V})$ were present in the solid phase, which will be oxidized to $\mathrm{Cr}(\mathrm{VI})$ in the dissolution process of the chemical separation, the difference of the results could be explained. As $\mathrm{Cr}(\mathrm{IV})$ and $\mathrm{Cr}(\mathrm{V})$ are considered instable for most conditions, this assumption has to be regarded with caution. Consequently, methods such as RAMAN, FTIR or EPR have to be tried to tackle this problem. In general, XANES offers a good capability to contribute to speciation analysis in solids.

Tab. 2 Comparison of the results of wet chemical analysis and XANES determination of Cr(VI) fraction in glass.

\begin{tabular}{|c|c|c|c|c|}
\hline \multirow{2}{*}{$\begin{array}{l}\text { Sample } \\
\text { number }\end{array}$} & \multicolumn{3}{|c|}{ Wet chemical procedure } & \multirow{2}{*}{$\begin{array}{c}\text { XANES } \\
\mathrm{Cr}(\mathrm{VI}) / \\
\mathrm{Cr}(\text { total }) \\
{[\%]}\end{array}$} \\
\hline & $\begin{array}{c}\mathrm{Cr}(\mathrm{VI}) \\
{[\mathrm{mg} / \mathrm{kg}]}\end{array}$ & $\begin{array}{l}\mathrm{Cr} \text { (total) } \\
{[\mathrm{mg} / \mathrm{kg}]}\end{array}$ & $\begin{array}{c}\mathrm{Cr}(\mathrm{VI}) / \\
\mathrm{Cr}(\text { total }) \\
{[\%]}\end{array}$ & \\
\hline 1 & 19.8 & 280 & 7.1 & 6.8 \\
\hline 2 & 191 & 541 & 35.3 & 34.0 \\
\hline 3 & $\begin{array}{c}125 \\
\text { Repeated } \\
127.6\end{array}$ & $\begin{array}{c}364 \\
\text { Repeated } \\
355.8\end{array}$ & $\begin{array}{l}34.3 \\
35.8\end{array}$ & 19.5 \\
\hline 4 & $\begin{array}{r}\text { Certified } 94 \\
95\end{array}$ & $\begin{array}{r}\text { Certified } 471 \\
480\end{array}$ & $\begin{array}{l}20.0 \\
19.8\end{array}$ & 20.0 \\
\hline
\end{tabular}

\section{Synchrotron Radiation Enhanced Growth of Gold Clusters in Glass}

In addition, SyXRF can successfully assist the development of new types of materials. Such an example is the controlled growth of gold clusters in Ca-Na-silicate glass [14]. An impressive property of such metal clusters is the size dependent excitation of so called surface plasmon polaritons. The interaction of a photon with the cluster at resonance generates a collective oscillation state of conducting electrons [15]. The resonance conditions depend e.g. on the size, the morphology and topology of the metal clusters. If these parameters can be controlled, the development of ultrafast optical switches in the $\mathrm{THz}$ region gets within reach. Especially, gold clusters show a promising potential for creating future nano-circuits. Being still far from technical realization there is a necessity of finding the methods how to influence size, morphology etc. systematically. Glasses composed of $70 \mathrm{SiO}_{2} \cdot 20 \mathrm{Na}_{2} \mathrm{O} \cdot 10 \mathrm{CaO}$ (values in mol \%) were doped with $0.02 \mathrm{~mol} \% \mathrm{AuCl}_{3} \cdot 2 \mathrm{H}_{2} \mathrm{O}$. Reagent-grade $\mathrm{SiO}_{2}, \mathrm{Na}_{2} \mathrm{CO}_{3}, \mathrm{CaCO}_{3}$, and $\mathrm{AuCl}_{3} \cdot 2 \mathrm{H}_{2} \mathrm{O}$ were used as starting materials. Approximately 35-g batches were mixed and melted at $1450{ }^{\circ} \mathrm{C}$ for $90 \mathrm{~min}$ in an electric furnace. The glass melt was then slowly cooled down to room temperature and cut, samples were polished to sizes of $10 \times 10 \times 1.00 \mathrm{~mm}^{3}$.

To confirm the gold concentration in the glass, the samples have been examined with SyXRF. The result of the SyXRF measurement was, that the gold concentration in the glass is 0.005 weight $\%(0.002 \mathrm{~mol} \%)$, one order of magnitude less than expected. This means, assuming a uniform distribution of the particles, each gold atom occupies a cube with 14 $\mathrm{nm}$ side length. The mechanism which leads to the loss of gold is not quite clear [16]. 


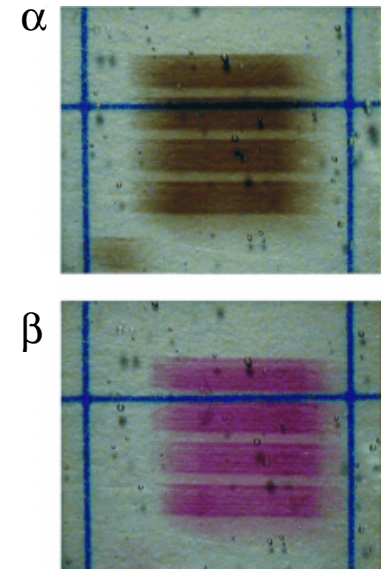

a)

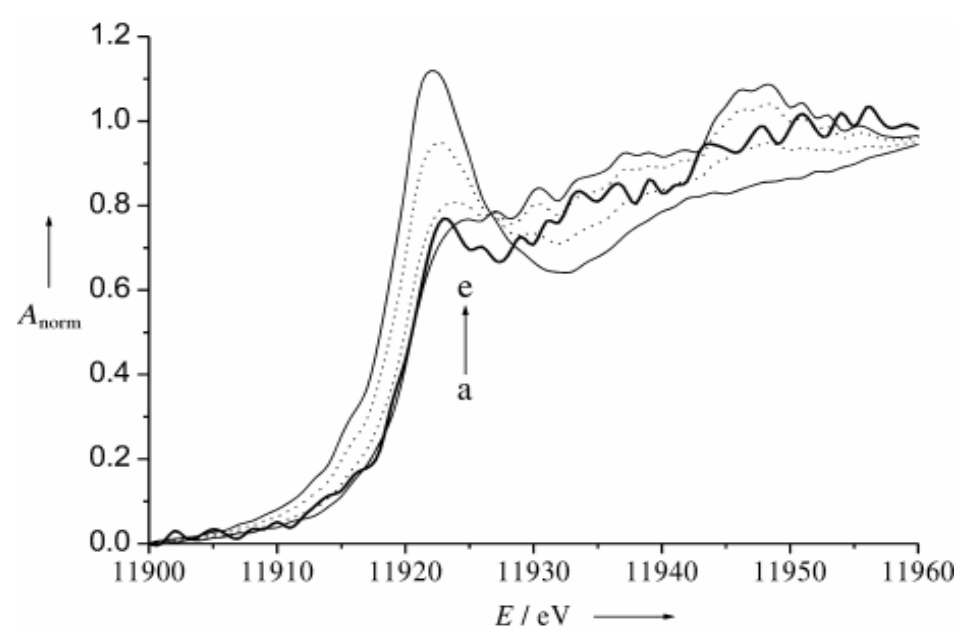

b)

Fig. 5 a: Light-microscopy images of a gold silicate glass after activation with 32-keV synchrotron radiation $\alpha$ ) before thermal annealing, $\beta$ ) after annealing at $550{ }^{\circ} \mathrm{C}$ for $30 \mathrm{~min}$. The pattern consists of spots with a size of $0.5 \times 1.0 \mathrm{~mm}^{2}$. The distance between the lines of the blue grid is $5 \mathrm{~mm}$.

Fig. 5 b: Normalized Au $\mathrm{L}_{\mathrm{III}}$-edge XANES spectra of different gold samples (solid lines) and spectra composed additively of reference spectra (dashed lines) obtained from a) gold silicate glass activated with synchrotron radiation; b) $\mathrm{Au}$ film; c) $0.2 \mathrm{Au}_{2} \mathrm{O}_{3}+0.8 \mathrm{Au}$ film; d) $0.6 \mathrm{Au}_{2} \mathrm{O}_{3}+0.4 \mathrm{Au}$ film; e) $\mathrm{Au}_{2} \mathrm{O}_{3}$.

During the XRF measurements it has been observed that the glass changed colour. This induced the idea to irradiate the glass to force this colouring.Therefore selected samples were irradiated with a photon flux density of $10^{12}$ photons $\mathrm{mm}^{-2} \mathrm{~s}^{-1}$ on a defined area with states X-ray radiation (32 keV) for $300 \mathrm{~s}$. During this irradiation the activated area turned brownish (Fig. 5a). In the subsequent thermal treatment the glass samples were placed into a platinum crucible and annealed in a muffle furnace.

Subsequently $\mathrm{Au} \mathrm{L}_{\mathrm{III}}$-edge XANES spectroscopy was used to study the effect of synchrotron radiation on the oxidation state. In our studies a gold film with a thickness of $40 \mathrm{~nm}$ on silica glass and gold(III) oxide were used as reference materials. The cationic gold standard shows distinct white lines (caused by transitions of $2 p$ electrons into vacant $5 \mathrm{~d}$ states) at $11922 \mathrm{eV}\left(\mathrm{Au}^{\mathrm{III}}\right)$ and can be clearly distinguished from $\mathrm{Au}^{0}$ samples, whose spectra do not show any white lines. A XANES spectrum was recorded for the activated area of a gold silicate glass. If the oxidation states \pm 0 and/or + III of gold exist in the sample, its spectrum should be composed additively of the reference spectra. Therefore the spectra of the gold film and gold(III) oxide were added in different proportions (Fig. 5b). The $\mathrm{L}_{\mathrm{III}}$ edges of the gold film and gold silicate glass were found to match almost exactly. The white line at $11922 \mathrm{eV}$ in the glass spectrum also indicates a minor fraction of gold(III). To confirm the assumptive composition extinction and SAXS measurements can be performed.

Using new optics at the BAMline, it will be possible to activate the glass with a spatial resolution in the $\mu \mathrm{m}$ range and to write structures inside of the glass. Combined with a spatially resolved tempering, this can even be used to create three dimensional optically active structures. 


\section{Investigation of Unique Objects of Art by X-Ray Fluorescence}

When scientific problems arise regarding origin, history or restauration of unique and valuable objects of art and methods of natural science are able to help, non-destructive testing is especially welcome. The division of nuclear analysis at BAM has a long tradition of "NDT meets art". Since the BAMline was put into routine operation in 2002, sensitive silver point drawings of Dürer, van Eyck and other artists were investigated. The results were of use to the custodies of the museums and are documented here [17][18]. Another branch was the analysis of gold objects. In this context the most prominent piece was the Sky Disc of Nebra, a roughly 3600 years old reproduction of the sky. On the disk there are 32 stars, two of originally three curved gold bands along the rim and two complete celestial forms which probably represent the sun and moon or, alternatively, the full and a crescentshaped moon. Two of the curved gold bands on the rim most likely represent horizons while the third one is interpreted as a celestial bark. Most of the stars seem to be arranged in an aesthetic way with aiming to fill the empty spaces between the larger objects more or less regularly. However, a constellation of seven stars can be clearly identified as a representation of the Pleiades whose visibility in the evening sky has been used for calendrical purposes in many cultures.

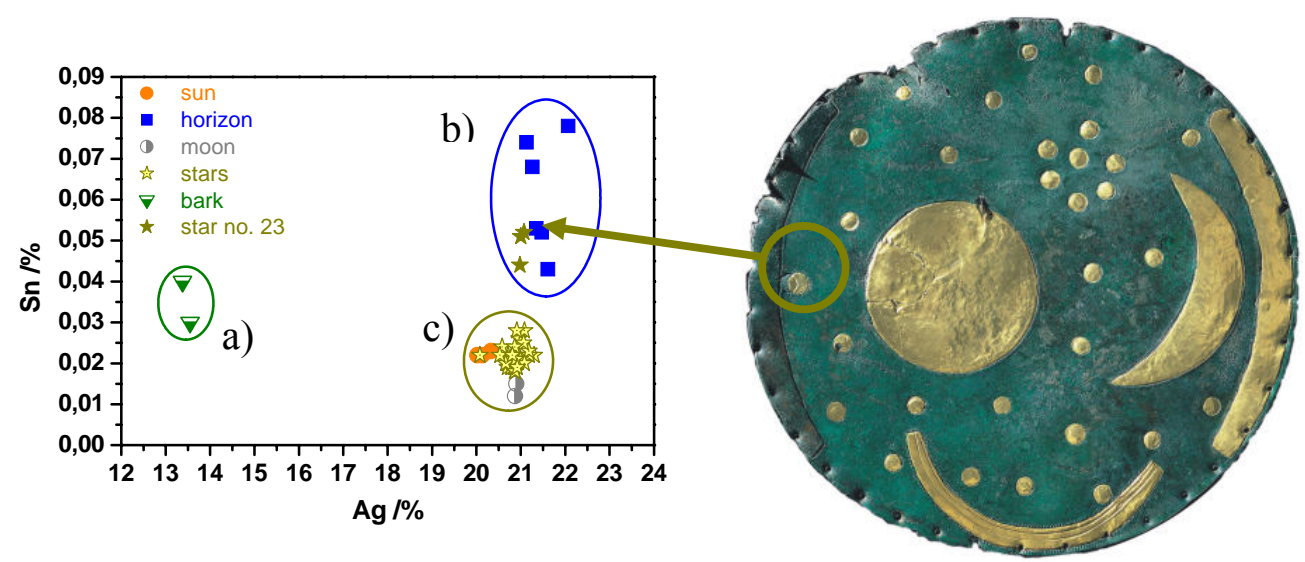

Fig. 6 The sky disk of Nebra and the measured silver and tin contents of the gold applications. The three groups are clearly to recognize: a) bark; b) star no. 23 and horizon c) the remaining stars with moon and sun.

The question was, whether this composition was of common origin or had developed step by step in different periods of completion according to the purpose of the disc. SyXRF of minor components such as silver and tin gave the basis of a cluster analysis resulting in the separation of three distinctly different groups: 1. sun, moon and the majority of the stars, 2. horizon and one single shifted star and 3. the so called bark. This supports the theory that the disc was completed in four phases, representing progress in knowledge and a change of religion and purpose. The first step was a reproduction of the sky, including the Pleiades as a marker for seed and harvest. In the second phase, the horizon directing with its end to the top of the famous hill "Brocken" in Harz Mountains and taking into account the momentary points of sunrise and sunset it could be used as some sort of calendar. In the third phase the bark, transporting the sun from the point of set to the point of rise, was added. This is a clear hint at Egyptian influences in Europe even during the bronze age.

In a fourth phase many equidistant holes have been drilled near the circumferential rim of the disc. Their purpose is not known up to now. This example and many others show that the cooperation of different disciplines can lead to new insights and that methods 
developed for purpose of natural science and technology may help to clear up details of our cultural heritage [19].

\section{Conclusions}

The use of synchrotron radiation at BAM for various types of analysis of solid samples could be demonstrated successfully. Main results are the implementation of reflectometry on thin surface layers and the qualification of energy dispersive X-ray fluorescence for certification and its use for highly specialized analyses, first examples of X-ray absorption spectrometry for speciation analysis of chromium and gold in glass. Analysis of unique objects of art was introduced as a by-product being of broad interest to the public.

In future the certification of trace elements has to be complemented by that of minor and major components through introduction of synchrotron radiation based wavelengthdispersive X-ray fluorescence (SyWDXRF) and more sophisticated evaluation schemes including general Monte Carlo codes and improved fundamental parameters.

Moreover, X-ray absorption spectrometry has to be combined with other methods of structural analysis in order to strengthen the reliability of statements deductions and to open new ways for solving problems.

Finally, the experimental environment has to be completed primarily by versatile insitu capabilities.

\section{Acknowledgement}

The authors would like to acknowledge the BESSY team for the good cooperation. We thank the Landesamt für Archäologie Sachsen-Anhalt as well as Prof. Pernicka for the possibility to examine the sky disc at the BAMline. Dr Reiche and Dr. Merchel for the collaboration during the many occasions we met art. 


\section{References}

[1] Funk T, Deb A, George SJ, Wang HX, Cramer SP; X-ray magnetic circular dichroism - a high energy probe of magnetic properties; COORDINATION CHEMISTRY REVIEWS 249 (1-2): 3-30 JAN 2005

[2] Illerhaus B, Hort N, Potzies C, Frank H, Goebbels J; Non-destructive Testing of Cast Magnesium Alloys by Computerized Tomography, Proc. of the 6th Int. Conference Magnesium Alloys and their Applications, 18-20 Nov 2003, Wolfsburg, Ed. K.U. Kainer,Wiley-VCH, pp. 746-751, ISBN 3-52630975-6 2003

[3] Müller BR, Hentschel MP; Synchrotron radiation refraction topography for characterization of lightweight materials; X-RAY SPECTROMETRY 33 (6): 402-406 NOV-DEC 2004

[4] Ueda K; Core excitation and de-excitation spectroscopies of free atoms and molecules;

JOURNAL OF THE PHYSICAL SOCIETY OF JAPAN 75 (3): Art. No. 032001 MAR 2006

[5] Schneider G; X-ray microscopy: methods and perspectives; ANALYTICAL AND BIOANALYTICAL CHEMISTRY 376 (5): 558-561 JUL 2003

[6] Riesemeier H, Ecker K, Görner W, Müller BR, Radtke M, Krumrey M; Layout and first XRF applications of the BAMline at BESSY II; X-RAY SPECTROMETRY 34 (2): 160-163 MAR-APR 2005

[7] Rehr JJ, Albers RC; Theoretical approaches to X-ray absorption fine structure; REVIEWS OF MODERN PHYSICS 72 (3): 621-654 JUL 2000

[8] Reinholz U, Weise HP, Brzezinka KW, Bremser W; Wasserstoff in amorphen Siliziumschichten, Zertifizierungsbericht BAM, in preparation

[9] Recknagel S, Lange B, Richter S; Bericht zur Zertifizierung der Elementspurengehalte in vier Reinkupferproben BAM-M381 bis BAM-M384, März 2006

[10] Noack S; Zertifizierungsbericht zum BAM-Referenzmaterial BAM-M315 (A1Si9Cu3), Bundesanstalt für Materialforschung und -prüfung (BAM),

Berlin, 2006

[11] Matschat R, Dette A, Guadagnino E; The certification of mass fractions of hexavalent chromium and of total chromium in glass, BAM-S004,Final certification report,Berlin,2003 http://www.bam.de/pdf/service/referenzmaterialien/zertifikate/special_materials/bam_s004report.pdf

[12] Guagnino E, Sundberg P, Corumluoglu O; A collaborative study on the determination of hexavalent chromium in container glasses, Glass Technol.; 2001, 42 (6), 148-152

[13] Pattison DI, Levina A, Davies MJ, Lay PA; An Investigation of the Chromium Oxidation State of a Monoanionic Chromium Tris (catecholate) Complex by X-ray Absorption and EPR Spectroscopies, INORG. CHEM. 40: 214-217, 2001

[14] Eichelbaum M, Rademann K, Müller R, Radtke M, Riesemeier H, Görner W; On the chemistry of gold in silicate glasses: Studies on a nonthermally activated growth of gold nanoparticles; ANGEWANDTE CHEMIE-INTERNATIONAL EDITION 44 (48): 7905-7909 2005

[15] Kreibig U, Vollmer M; Optical Properties of Metal Clusters; Springer Series Materials Science 25, Springer 1995

[16] Eichelbaum M; Über das Aktivierte Wachstum von Edelmetall-Clustern mit Synchrotron-Strahlung; Diploma Thesis, , Humboldt Universität Berlin 2005

[17] Reiche I, Radtke M, Berger A, Görner W, Ketelsen T, Merchel S, Riederer J, Riesemeier H, Roth M; Spatially resolved synchrotron-induced X-ray fluorescence analyses of metal point drawings and their mysterious inscriptions; SPECTROCHIMICA ACTA PART B-ATOMIC SPECTROSCOPY 59 (10-11): 1657-1662 OCT 82004

[18] Reiche I, Radtke M, Berger A, Görner W, Merchel S, Riesemeier H, Bevers H; Spatially resolved synchrotron radiation induced X-ray fluorescence analyses of rare Rembrandt silverpoint drawings; APPLIED PHYSICS A-MATERIALS SCIENCE \& PROCESSING 83 (2): 169-173 MAY 2006

[19] Pernicka E, Radtke M, Riesemeier H, Wunderlich CH; European Network of Competence at 1600BC; BESSY Highlights 2003 - Scientific Highlights 2004 